Instituto de Estudos Sócio-Ambientais

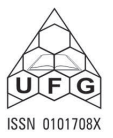

BOLETIM GOIANO DE GEOGRAFIA

v. 26, n. 1, jan./jun. 2006

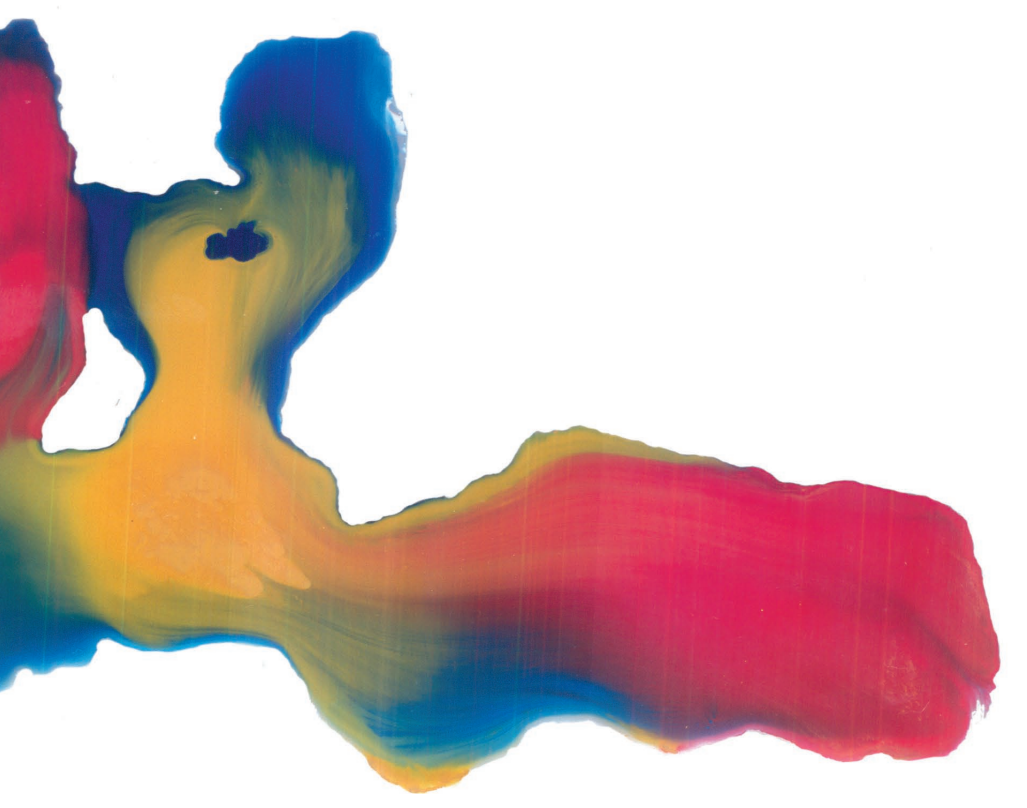

$\infty$
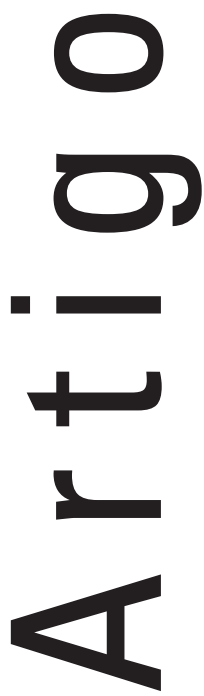


\title{
ACIONANDO TERRITÓRIOS: A MOBILIDADE NA REGIÃO METROPOLITANA DE GOIÂNIA E EM APARECIDA DE GOIÂNIA
}

\author{
ACTIVATING TERRITORIES: CONSIDERATIONS ON THE MOBILITV IN GOIANA \\ METROPOLITAN
}

Tadeu Alencar Arrais - IESA/UFG

tadeuarrais@ibest.com.br

\section{Resumo}

No presente artigo procuramos elaborar uma leitura crítica sobre a mobilidade na Região Metropolitana de Goiânia, utilizando como suporte a categoria território. Partimos do entendimento que, ao deslocarem-se no espaço intra-metropolitano, os indivíduos acionam territórios com conteúdos e funcionalidades diferentes, expressando tanto uma hierarquia entre os lugares quanto uma hierarquia entre os indivíduos. Para apoiar nossos argumentos, utilizaremos dados regionalizados sobre os deslocamentos pendulares e o perfil ocupacional dos indivíduos que se desclocam de Aparecida de Goiânia, muncipio de maior nível de intregracao com Goiânia. Mostraremos que essa integração ocorre de forma desigual, reproduzindo, nesse município, um padrão de organização territorial também desigual.

Palavras-chave: mobilidade, região metropolitana, território.

\begin{abstract}
This article focus on the mobility in Goiana Metropolitan Area from the point of view of the territory category. We understand that, when moving in intra-metropolitan space, individuals activate territories with diverse contents and functionalities, expressing not only a hierarchy betwen places but also among individuals themselves. To support our thesis, we analyse both regionalized data on commuting and the profile of individuals who commute from Aparecida de Goiânia, Goiânia's most integrated neighboring town. We will be able to show that such an integration occurs in a quite irregular way, thus producing, in that town, an irregular territorial organization.
\end{abstract}

Key-words: mobility, metropolitan area, territory. 


\title{
Considerações iniciais
}

\author{
Se não é fácil controlar a natalidade \\ e a mortalidade, também não é simples \\ controlar a mobilidade, ainda que isso dependa \\ dos meios de que dispõem as organizações \\ interessadas em modificar as repartições, as distribuições \\ dos homens no espaço. \\ C. Raffestin, Por uma geografia do poder, p. 88.
}

A constituição das Regiões Metropolitanas brasileiras teve estreita relação com o reconhecimento de um padrão de interações espaciais hierárquicas e polarizadas entre municípios de uma mesma unidade territorial. ${ }^{1}$ A análise da mobilidade foi uma das maneiras utilizadas para determinar o padrão dessas interações espaciais. No sentido geral, a mobilidade pode ser definida como o deslocamento de pessoas, bens e/ou capitais de um lugar para o outro. Essa definição, porém, carece de precisão conceitual, especialmente porque toma deslocamento espacial como sinônimo de mobilidade. Para os propósitos desta reflexão utilizaremos o conceito desenvolvido por Levy (2002), para quem a mobilidade é uma relação social construída a partir da mudança de lugar. É relação social porque, segundo o autor, a mobilidade envolve uma acessibilidade (presença dos sistemas de circulação e transporte) e uma competência (o acesso a partir do preço). Acessibilidade e competência formam, ainda segundo este autor, um capital social para os indivíduos que os detêm.

A análise Levy (2002) reforça a noção de que o deslocamento coloca os indivíduos em contato com territórios com conteúdos, normas e formas diferentes. A utilização da categoria território ajuda a desviar da compreensão da mobilidade como uma relação mecânica em um espaço de conteúdo abstrato. Muitos autores, dentre os quais Haesbaert (2002), salientam a importância da categoria território para as ciências sociais, reafirmando sua vinculação com as relações de poder que ultrapassam a visão onipresente do Estado. Poder e território, nesse sentido, não se limitam à figura do Estado, de tal modo que o território perde em estabilidade e ganha na dimensão temporal a partir uso que os indivíduos fazem dele, como já apontou Souza (1995). Segundo este autor (1995, p. 87): 
Territórios, que são no fundo antes relações sociais projetadas no espaço que espaços concretos (os quais são apenas os substratos materiais das territorialidades - voltar-se-á a isso mais adiante), podem, conforme já se indicara na introdução, formar-se e dissolver-se, constituir-se e dissipar-se de modo relativamente rápido (ao invés de uma escala temporal de séculos ou décadas, podem ser simplesmente anos ou mesmo meses, semanas ou dias), ser antes instáveis que estáveis ou, mesmo, ter existência regular, mas apenas periódica, ou seja, em alguns momentos - e isto apesar de que o substrato espacial permanece ou pode permanecer o mesmo.

Na medida em que se movem, circulam, os indivíduos acionam territórios com normas diferentes, colocando-se, diante desses territórios, em condições de poder diferenciadas, tal quais os migrantes pendulares. É importante destacar que as normas não são as normas "do" território ou criadas "pelo" território. São, antes, normas "projetadas” no território por indivíduos concretos. Daí a relevância do entendimento do conceito de territorialidade. De acordo com Sack (1986, p. 219):

A territorialidade, como um componente do poder, não é apenas um meio para criar e manter a ordem, mas é uma estratégia para criar e manter grande parte do contexto geográfico através do qual experimentamos o mundo e o dotamos de significado.

Em Sack (1998) percebemos a valorização da dimensão temporal da “territorialidade”, ou seja, a idéia de influenciar implica num horizonte temporal que depende, diretamente, das circunstâncias dinâmicas em que estão inseridos os indivíduos que "ativam” ou "desativam" suas territorialidades, dominando, influenciando ou controlando pessoas e recursos. Por isso, como destaca Raffestin (1993), a territorialidade é uma relação entre atores, expressando uma ligação complexa destes na construção e reconstrução dos seus territórios.

Ao propormos considerar a mobilidade a partir da análise das relações entre o território de destino e os territórios de partida, estamos destacando a importância de leituras que possam complementar a perspectiva quantitativa. Isso alerta para o fato de que, diariamente, os indivíduos entram nos circuitos de relações econômicas, políticas, afetivas e culturais nos diferentes territórios da RMG. Acionar um território não significa estar em condições de controlá-lo. Ao contrário, aqueles que acionam um território podem estar subordinados às suas normas, condição peculiar à parcela dos migrantes pendulares da RMG. 


\section{O deslocamento na RMG}

São muitos os fatores que podem ou não dificultar o deslocamento de pessoas de um território para outro, dentre os quais podemos arrolar: 1) questões relacionadas aos limites etários (dificuldades no deslocamento em virtude da idade); 2) condições naturais de um dado território (uma barreira natural como um deserto ou mesmo uma serra a ser transposta); 3) as condições sócio-econômicas dos sujeitos que se deslocam (ausência de recursos para condução diária). Desses fatores, no atual estágio do desenvolvimento técnico científico, certamente o último, por depender diretamente da renda, é aquele que exerce maior influência nas regiões metropolitanas brasileiras. Vejamos os dados sobre os deslocamentos na RMG.

O movimento de pessoas de 15 anos e mais de idade que estudam ou trabalham fora dos municípios da RMG demonstra uma forte migração pendular em direção a Goiânia. Os dados da tabela 1 dizem respeito a $71,35 \%$ da população total da RMG em 2000, perfazendo um total de 846.242 pessoas. Desse total, 13,2\% trabalham ou estudam em outro município. As relações sociais (de produção, políticas, afetivas etc), dessa forma, também são construídas no deslocamento, na mudança de lugar. Trabalhar em um lugar, estudar em outro e residir em um terceiro, é situação comum nas grandes cidades, o que prova os argumentos que reconhecem uma fragmentação cada vez maior da vida cotidiana nos ambientes metropolitanos.

Desconsiderando Goiânia, o total da população de 15 anos ou mais que trabalhava ou estudava em outro município da RMG, no ano de 2000, foi de 97.140 pessoas. Desse total, 93,11\% deslocaram-se para Goiânia. Entre os municípios como maior percentagem de deslocamento para fora do município, estavam Senador Canedo (47,8\%), Aparecida de Goiânia $(43,3 \%)$ e Goianira (35,9\%). A população que se deslocou desses três municípios equivalia a $74,83 \%$ do total que se deslocou para fora dos municípios na RMG. Excluindo Goiânia, essa percentagem sobe para 86,6\%. Os demais municípios ficaram em uma longa faixa, onde encontramos Goiânia com 2,6\%, Goianápolis com 4,8\%, Hidrolândia com 11,5\%, Nerópolis com 12,8\%, Aragoiânia com 13,1\%, Santo Antônio de Goiás com 21\%, Trindade com 25,9\% e Abadia de Goiás com 30,4\%. A pouca expressividade dos dados de Goiânia é compreensível, por sua característica de cidade receptora dos deslocamentos diários. Goianápolis é o município com menor grau de dependência com 
Goiânia. Trata-se do único município da RMG que a população que se destina ao pólo (36 pessoas) é menor que a que se destina aos outros municípios (186 pessoas). Percebe-se que, em relação ao deslocamento para o pólo, exceção feita para este último município, os demais apresentaram porcentagem superior a $78,7 \%$.

Tabela 1: Municípios da Região Metropolitana de Goiânia segundo População Residente de 15 Anos e Mais de Idade que Trabalha ou Estuda e Pessoas que Realizaram Movimento Pendular - 2000

\begin{tabular}{|c|c|c|c|c|c|c|c|c|}
\hline \multirow[b]{3}{*}{ Municípios } & \multirow{2}{*}{\multicolumn{2}{|c|}{$\begin{array}{c}\text { Distância } \\
\text { rodoviária } \\
\text { e vias de } \\
\text { acesso }\end{array}$}} & \multicolumn{4}{|c|}{ Número de pessoas de 15 anos e mais de idade } & \multirow{3}{*}{$\begin{array}{c}\mathrm{C} / \mathrm{B} \\
(\mathrm{em} \%)\end{array}$} & \multirow{3}{*}{$\begin{array}{c}\mathrm{D} / \mathrm{C}^{2} \\
\text { (em \%) }\end{array}$} \\
\hline & & & \multirow[b]{2}{*}{$\begin{array}{c}\text { Total } \\
\text { (A) }\end{array}$} & \multicolumn{3}{|c|}{ Que trabalham ou estudam } & & \\
\hline & $\begin{array}{l}\mathrm{Em} \\
\mathrm{Km}\end{array}$ & Acesso & & $\begin{array}{l}\text { Total } \\
\text { (B) }\end{array}$ & $\begin{array}{l}\text { Fora do mu- } \\
\text { nicípio de } \\
\text { residência }{ }^{1} \\
\text { (C) }\end{array}$ & $\begin{array}{l}\text { Dirigindo- } \\
\text { se ao pólo } \\
\text { metropo- } \\
\text { litano } \\
\text { (D) }\end{array}$ & & \\
\hline $\begin{array}{l}\text { Abadia de } \\
\text { Goiás }\end{array}$ & 27 & BR-060 & 3.400 & 2.319 & 705 & 620 & 30,4 & 87,9 \\
\hline $\begin{array}{l}\text { Aparecida de } \\
\text { Goiânia }\end{array}$ & 21 & BR-153 & 228.427 & 161.675 & 69.958 & 66.164 & 43,3 & 94,6 \\
\hline Aragoiânia & 42 & GO-040 & 4.550 & 3.037 & 398 & 332 & 13,1 & 83,4 \\
\hline Goianápolis & 33 & $\begin{array}{l}\text { BR-457 } \\
\text { GO-415 }\end{array}$ & 7.318 & 4.603 & 222 & 36 & 4,8 & 16,3 \\
\hline Goiânia & - & - & 812.707 & 589.498 & 15.352 & 0 & 2,6 & 0,0 \\
\hline Goianira & 37 & GO-070 & 12.934 & 8.417 & 3.021 & 2.748 & 35,9 & 91,0 \\
\hline Hidrolândia & 36 & BR-153 & 9.291 & 6.104 & 704 & 593 & 11,5 & 84,3 \\
\hline Nerópolis & 42 & GO-080 & 13.049 & 9.203 & 1.176 & 926 & 12,8 & 78,7 \\
\hline $\begin{array}{l}\text { Santo Antônio } \\
\text { de Goiás }\end{array}$ & 38 & GO-080 & 2.167 & 1.452 & 305 & 265 & 21,0 & 87,1 \\
\hline $\begin{array}{l}\text { Senador } \\
\text { Canedo }\end{array}$ & 16 & GO-403 & 35.065 & 23.410 & 11.199 & 10.475 & 47,8 & 93,5 \\
\hline Trindade & 30 & GO-060 & 56.975 & 36.524 & 9.453 & 8.289 & 25,9 & 87,7 \\
\hline Total & - & - & 1.185 .883 & 846.242 & 112.493 & 90.448 & 13,3 & 80,4 \\
\hline
\end{tabular}

Fonte: IBGE. Censo demográfico 2000. SEPLAN-GO (2003).

${ }^{1} \mathrm{O}$ movimento de pessoas que estudam ou trabalham fora de seu município de residência é denominado de pendular.

${ }^{2} \mathrm{O}$ cálculo do percentual de pessoas que se dirigem ao pólo, relativo ao "total região metropolitana", exclui os dados do município pólo. 
n. 1, (26): 91-114, 2006

Artigo

Figura 1: Região metropolitana de Goiânia - deslocamentos para trabalho ou estudo de pessoas de 15 anos e mais de idade em outro município do estado

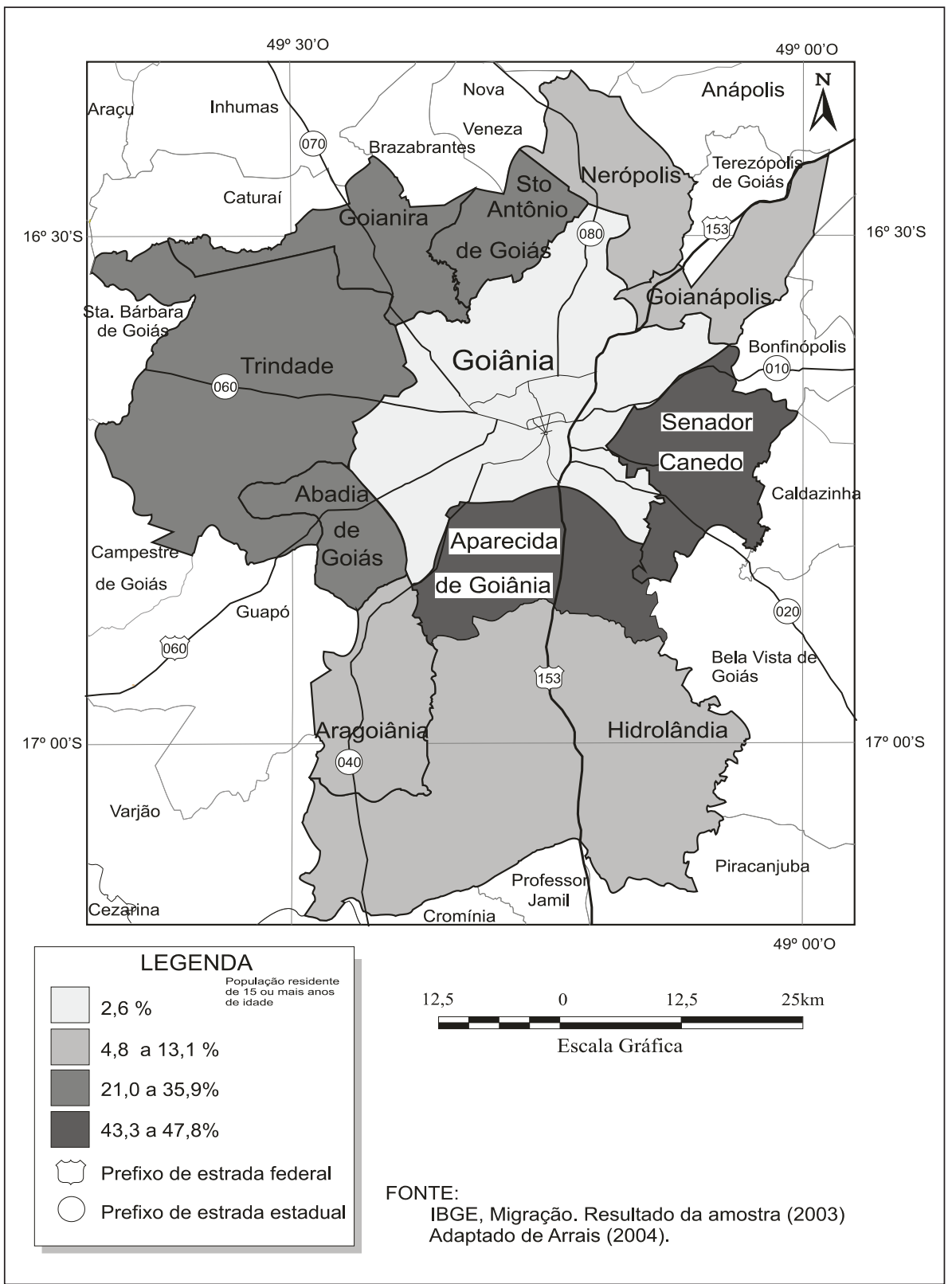


Avaliando a Tabela 1 e excluindo Goiânia, constata-se que apenas 6.152 pessoas, dentre aqueles que se deslocaram para os municípios da RMG em 2000, não o fizeram para o município pólo. Os dados sobre os deslocamentos laterais (entre os municípios periféricos) são os seguintes: Nerópolis com $21,3 \%$ de sua população em outro município, provavelmente com migração pendular para Santo Antônio de Goiás, Nova Veneza ou mesmo Anápolis, município com o qual ainda mantém muitos vínculos, facilitados a partir da GO-222. Em seguida aparece Aragoiânia, com 16,6\% de deslocamento para outro município, provavelmente com grande participação de Aparecida de Goiânia, uma vez que este último município encontra-se em nível superior de polarização, estando ainda no caminho para Goiânia, pelo acesso da GO-040. Muito embora tenha apenas 5,4\% de deslocamento para outros municípios, Aparecida de Goiânia apresentou o maior número absoluto, com 3.794 pessoas. Os vínculos realizam-se, prioritariamente, com os municípios de Hidrolândia, Aragoiânia e também Anápolis, especialmente no deslocamento para o estudo.

Interessante observar a relação entre a forma da RMG, as vias de acesso rodoviário e a distância de Goiânia. Alguns desses municípios distam mais de 30 km de Goiânia, como Aragoiânia (42 km), Santo Antônio de Goiás (38 km) Goianira (37 km), Hidrolândia (36 km) e Goianápolis (33 km). Entretanto, essa distância não é, necessariamente, o fator determinante para a integração, mesmo porque ela refere-se à sede dos municípios e os vetores de integração não ocorrem apenas pelas vias apontadas, em virtude da progressiva conurbação, especialmente entre os municípios de Aparecida de Goiânia (21 km), Goianira (37 km), Senador Canedo (16 km) e Trindade (30 km). O fluxo de pessoas entre Aparecida de Goiânia e Goiânia, por exemplo, tanto pode ocorrer pela BR-153, quanto pelas vias municipais, como é o caso da Avenida São Paulo ou mesmo Rio Verde, entre outras possibilidades. Já em relação a municípios como Aragoiânia (42 km), Nerópolis (42 km) e Goianápolis $(33 \mathrm{~km})$, a distância e a disponibilidade de transporte exerce maior influência.

Outro fator que pode ser relacionado ao deslocamento para o pólo refere-se à taxa de crescimento geométrico entre 1991/2000. Neste período, o crescimento populacional de Goiânia foi de 1,94\%, apenas maior que Abadia de Goiás, com 1,82\%. Os três municípios com maior deslocamento para o pólo, por exemplo, estão entre aqueles com maior taxa de crescimento geométrico da RMG: Senador Canedo (9,27\%), Aparecida de Goiânia (7,3\%), Santo Antônio de Goiás (6,17\%) e Goianira (6,0\%) (IBGE, 2003). 
Essa característica (maior crescimento da periferia em relação ao pólo) deve-se às ligações estabelecidas entre as pessoas que moravam e trabalhavam em Goiânia e mudaram para a periferia metropolitana, o que corroborou para a manutenção dos vínculos de dependência com o pólo. É muito comum pessoas mudarem de Goiânia para outros municípios da RMG e, ainda assim, manterem vida de relações, especialmente para trabalho e estudo. Essa hipótese confirma-se, por exemplo, quando analisamos os dados da RMG sobre Imigrantes de Data Fixa por Origem - 2000: 48,58\% dos migrantes de Aparecida de Goiânia, 52,36\% dos de Senador Canedo, 51,16\% dos de Goianira, 51,32\% dos migrantes de Hidrolândia, 59,03\% dos migrantes de Aragoiânia e 59\% dos migrantes de Abadia de Goiás, tem origem intrametropolitana. Em Goiânia esse número é de apenas 4,93\%, uma vez que $55,78 \%$ dos migrantes são classificados predominantemente na categoria interestadual (IBGE, 2001).

Utilizamos os dados sobre migração pendular e crescimento demográfico para argumentar que o deslocamento para o pólo relaciona-se com a origem das pessoas e com os vínculos estabelecidos anteriormente com Goiânia (seja para estudo, trabalho ou mesmo relações familiares). Nesse sentido, a relação que essa miríade de indivíduos mantém diariamente com Goiânia se dá a partir do acionamento de vários territórios. O próprio deslocar-se, a locomoção, pode ser considerada uma espécie de território complementar que permite acionar outros territórios na RMG, especialmente Goiânia.

\section{Território de destino}

A condição de centralidade Goiânia vincula-se diretamente com os deslocamentos pendulares. Escrevemos condição porque a centralidade é mutável, estando subordinada à dinâmica socioeconômica de uma dada sociedade. Quando falamos em centralidade não estamos referindo à dimensão geométrica. Por centralidade referimo-nos à condição que determinou que uma cidade como Goiânia concentrasse meios de consumo, serviços públicos, comércio, indústria, oportunidades de emprego, equipamentos de lazer etc., em detrimentos de outras cidades de sua região. A centralidade, dessa maneira, é sempre uma relação que expressa uma dada hierarquia entre indivíduos e grupos sociais traduzida numa hierarquia entre lugares, entre cidades, entre regiões etc. ${ }^{2}$ 


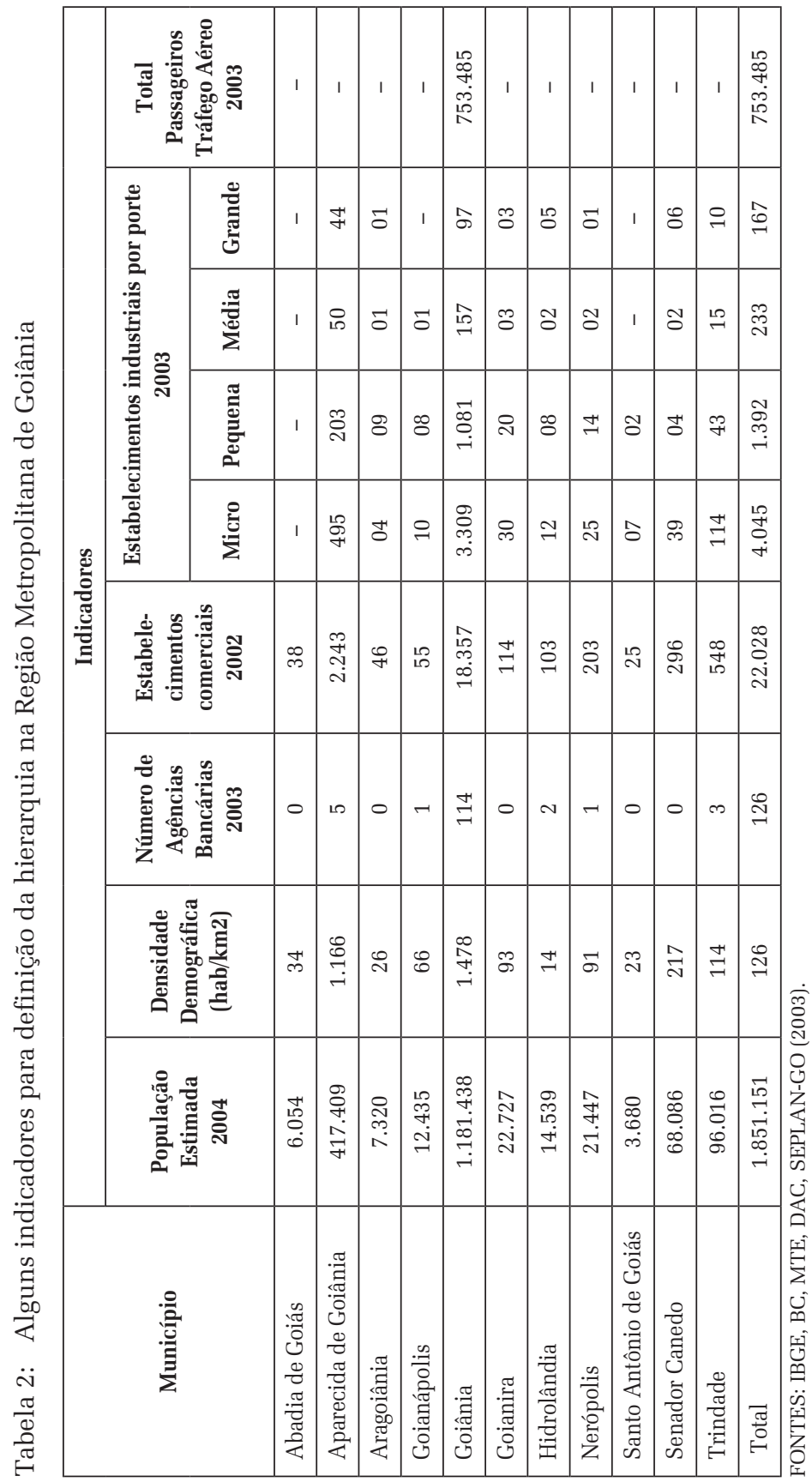


Os dados sobre os deslocamentos dispostos na tabela 1, confirmam os argumentos sobre a centralidade exercida por Goiânia. Desse modo, o deslocamento pode ser compreendido a partir da centralidade de Goiânia em relação direta com a pouca centralidade do restante dos municípios da RMG. De acordo com estimativas, Goiânia possuía em 2004, 63,82\% da população da RMG. Além da população, concentrava em 2003, 90,0\% das agências bancárias, além de sediar empresas de destaque nacional, isso sem contar o fato de reunir mão de obra qualificada e uma infra-estrutura de transporte que atente a RMG.

A pujança econômica condiz com a renda e a oferta de empregos que absorve a demanda dos demais municípios da RMG. O trabalho é um dos motivos mais freqüentes da mobilidade. ${ }^{3}$ Somado às maiores possibilidades de rendimento e empregabilidade, a economia de aglomeração possibilitou a concentração de serviços públicos e privados, o que, adicionado ao fato de o pólo ser uma capital de Estado, fez crescer a oferta de emprego.

Essa centralidade repete-se no comércio, uma vez que Goiânia detinha, em 2002, 83,33\% dos estabelecimentos comerciais. Por outro lado, a centralidade de Goiânia contradiz com o baixo nível de centralidade dos demais municípios, em todas as variáveis descritas na tabela 2. Apenas três municípios, nesse quesito, destacam-se: Aparecida de Goiânia, no limite Sul, aparece em segundo lugar em todos os indicadores, dado que reforça o argumento sobre uma tímida dispersão das atividades econômicas para o Sul de Goiânia. Trindade, no limite Leste de Goiânia, é o terceiro, seguido por Senador Canedo, no limite Oeste e, mais distante, Goianira, na divisa noroeste. Interessante que esses quatro municípios, em franco processo de conurbação, praticamente fecham o espaço do pólo, indicando a formação de futuras sub-centralidades.

Afora as considerações sobre a centralização, visíveis em qualquer análise ou mesmo visita à RMG, é importante salientar a forma como esse deslocamento ocorre, porque a condição de centralidade aconteceu ao mesmo tempo em que os meios de deslocamento (malha viária intra-metropolitana) foram sendo constituídos. Desse modo, há uma relação entre centralização (Goiânia), dispersão da população de baixa renda para os municípios periféricos e, ao mesmo tempo, existência de uma oferta de transporte precário do ponto de vista da qualidade, mas lucrativa para os grupos que monopolizam sua oferta.

Ao considerar Goiânia como um território de destino, afirmamos que aqueles que se deslocam estabelecem relações funcionalmente desiguais com a cidade, especiamente para o trabalho. É possível imaginar o drama pessoal, por exemplo, de uma pessoa que se desloca para Goiânia na busca 
de assistência médica, enfrentando, além dos transtornos com o transporte, postos de saúde congestionados. Trabalhar e estudar em Goiânia, morando em Aparecida de Goiânia ou Senador Canedo, especialmente para a população mais pobre, deixa esses indivíduos numa situação que beira a "precariedade territorial”, na acepção tomada por Haesbaert (2005). ${ }^{4}$ A cada dia esses indivíduos são mais destituídos do controle de seus territórios, sobrandolhes menos tempo para o convívio familiar e para as atividades lúdicas nos territórios de partida. Na verdade, podemos pensar numa progressiva perda de controle dos seus territórios, a partir do momento que estes indivíduos, a cada madrugada, deslocam-se para Goiânia. Daí a ligação umbilical entre o território de destino e os territórios de partida. O tempo que é consumido nos primeiros é subtraído dos segundos.

\section{Territórios de partida}

Na sua análise sobre as conseqüências da globalização, Bauman (1999) refere-se ao fato de a mobilidade ter se tornado um poderoso fator de estratificação social. De fato, sua análise reforça uma tendência de estudos sobre a relação entre mobilidade e imobilidade dos indivíduos no território como uma forma de exclusão social. Mas não se trata de uma relação simples, mesmo porque, convencionalmente, quando se pensa em deslocamento, existe uma tendência que valoriza o percurso e o destino, em detrimento da origem, ou do que podemos grosseiramente chamar de territórios de partida.

Os territórios de partida podem ser compreendidos, no sentido lato, como os municípios periféricos da RMG. Na verdade os municípios são uma referência para a reflexão, já que, como colocamos em outro momento (ARRAIS, 2004), existem diferenças intra-urbanas e forte segregação no interior desses municípios, como se pode verificar em Aparecida de Goiânia, onde já notamos bairros com excelente infra-estrutura, além de condomínios horizontais fechados que agregam a classe abastada daquele município. Vejamos brevemente algumas características dos municípios periféricos.

A análise da renda constitui-se um bom parâmetro para a compreensão dos territórios de partida, uma vez que tem relação direta com o deslocamento, pois acarreta em um custo que influencia a "escolha" dos bairros periféricos da RMG para moradia. O padrão de moradia, assim como o de deslocamento, reflete a condição social que, em uma sociedade capitalista, envolve a disposição de recursos para adquirir um imóvel, um automóvel, matricular-se em 


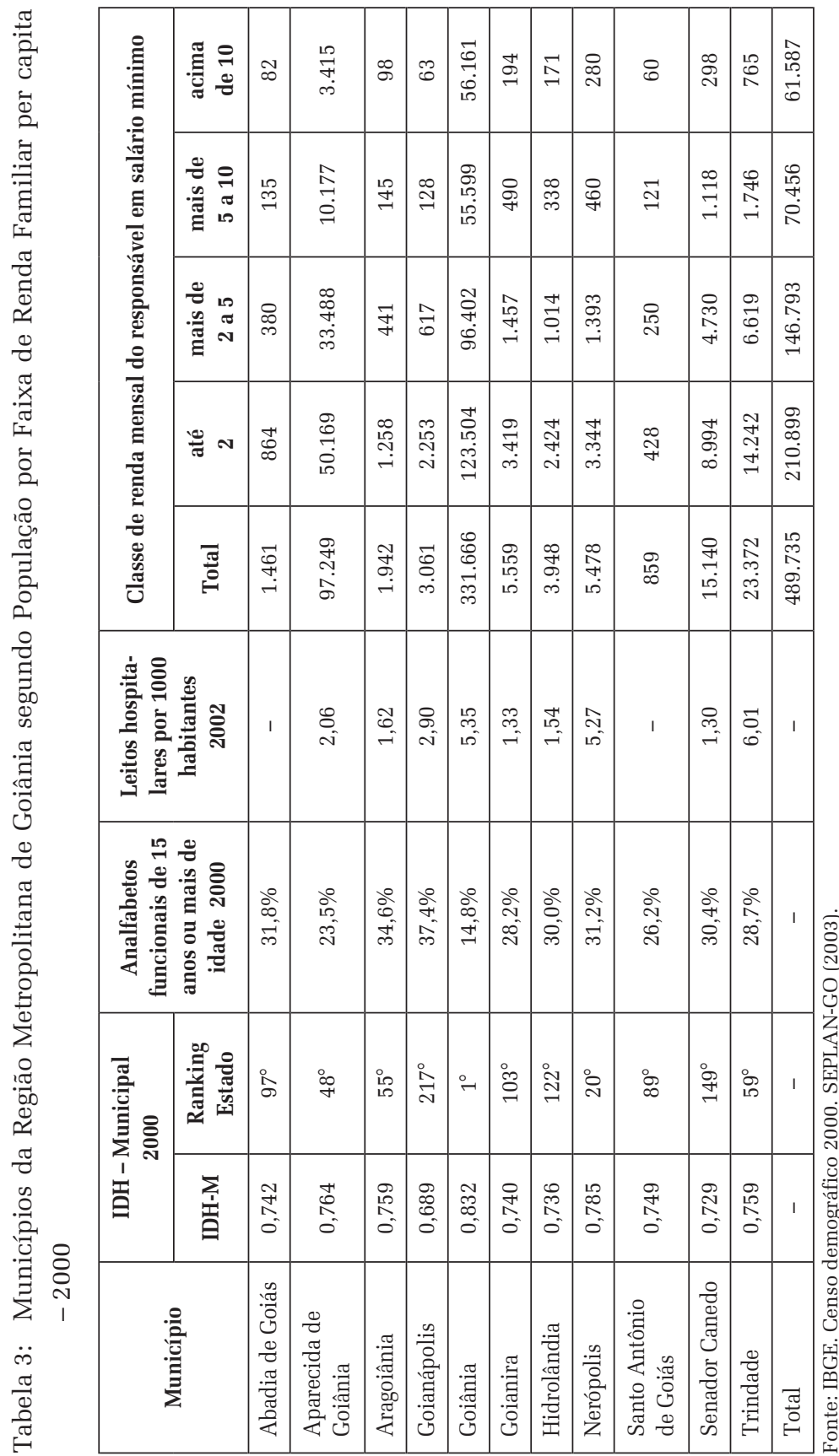


uma escola, locomover-se etc. Sabemos que a mobilidade, por constituir-se em capital social, tem um preço e que nem todos podem pagar, por isso mesmo ela é diferencial (Massey, 2000). Por outro lado, devido a expansão e especulação urbana, a população mais pobre foi empurrada para a periferia da RMG, aumentando, dessa forma, a distância espacial entre local de residência e os locais de trabalho-estudo, que podem variar de $16 \mathrm{~km}$ a $42 \mathrm{~km}$ na RMG. ${ }^{5}$ A periferia assume, dessa forma, a acepção trabalhada por Santos (1979, p. 229):

A palavra periferia pode ser utilizada em diferentes acepções. Cada disciplina científica pode lhe atribuir um significado próprio. Em termos geográficos, a periferia não será definida pela distância física entre um pólo e as zonas tributárias, mas antes em termos de acessibilidade. Esta depende essencialmente da existência de vias e meios de transporte e da possibilidade efetiva de sua utilização pelos indivíduos, com o objetivo de satisfazer necessidades reais ou sentidas como tais. Mas a incapacidade de acesso aos bens e serviços é, em si mesma, um dado suficiente para repetir o indivíduo, e também a firma, a uma situação periférica.

Tratando-se da RMG, os dados sobre classe de renda mensal do responsável do domicílio em salário mínimo, de 2000, contidos na tabela 3 , indicam a pouca centralidade dos municípios periféricos. Goiânia, na classe de renda de até dois salários mensais, é o município da RMG com menor participação percentual, com 37,23\% (123.504 pessoas). Os demais municípios estão na faixa entre 51,58\% (Aparecida de Goiânia) e 64,77\% (Aragoiânia). Na classe de renda mais de 2 a 5 salários mensais, Goiânia teve a participação de 29,06\%, perdendo para Aparecida de Goiânia com 34,43\%, Senador Canedo, 31,24\% e Santo Antônio de Goiás, com 29,10\%. Já na classe de mais de 5 a 10 salários mensais e acima de 10 salários mensais, Goiânia apresentou 16,76\% e 16,93\%, respectivamente. Bem diferente é a situação dos demais municípios. Na classe de renda mensal de mais de 5 a 10, a participação variou entre 4,1\% (Goianápolis) e 14,08\% (Santo Antônio de Goiás). Na classe acima de 10 salários mensais a variação esteve entre 1,9\% (Senador Canedo) e 6,9\% (Santo Antônio de Goiás).

Os municípios com menor participação nas classes de renda inferiores são justamente os periféricos, uma vez que a renda no pólo é maior nas classes acima de 5 salários mínimos. A classe de renda mensal tem como referência o domicílio e não o local de trabalho. Dessa forma, explica-se, por exemplo, a participação de Santo Antônio de Goiás com 14,08\% na classe de renda de mais de 5 e 10 salários mensais e 6,9\% na classe de renda acima de 10 salários mensais, desempenho inferior apenas para Goiânia. 
Os dados de renda aproximam-se dos outros indicadores sociais, como o número de leitos por 1000 habitantes em 2002, IDH-municipal de 2000 e analfabetos funcionais de 15 anos ou mais de idade, em 2000. A matemática parece simples: renda inferior, condições precárias de habitação, menores possibilidade de acesso aos equipamentos de saúde, menor nível de qualificação educacional, o que resulta nos menores indicadores no ranking municipal do Estado. Além disso, a população desses municípios ainda enfrenta, diariamente, o deslocamento para o pólo. A razão do deslocamento reside em um tipo particular de produção do espaço urbano que segrega os produtores e agrega a produção. Em outras palavras, centraliza a produção (em um espaço polarizado e nas mãos de determinados grupos sociais) e descentraliza aqueles que produzem, subordinando os territórios de partida ao território de destino. Não por acaso muitos desses municípios ainda guardam esse epíteto que reflete a dependência e sujeição de seus cidadãos à metrópole.

\section{Aparecida de Goiânia: um território de partida}

As referências ao município de Aparecida de Goiânia terão como base os resultados parciais do tabulamento dos dados da pesquisa desenvolvida pelo Observatório das Metrópoles, núcleo Goiânia. ${ }^{6}$ Do ponto de visa metodológico, a pesquisa investiga a relação entre a posição social dos indivíduos e a forma de ocupação do território. Com a pesquisa, desenvolvida também em outras regiões metropolitanas, tencionamos construir tipologias sócio-espaciais, relacionando as CATs (Categorias Ocupacionais) e as AEDs (Áreas de Expansão Demográfica), esta ultima resultado da agregação de setores censitários e/ou mesmo bairros. Para esta parte do artigo não utilizaremos as tipologias sócio-espaciais, apenas os instrumentos que permitiram sua construção, ou seja, as AEDs e as Categorias Ocupacionais. A base de dados utilizada foi o censo demográfico 2000. A RMG foi dividida em 66 AEDs, assim distribuídas: 39 (Goiânia), 4 (Trindade), 15 (Aparecida de Goiânia) e cada um dos demais municípios 01. Vejamos o exemplo de Aparecida de Goiânia.

No caso da mobilidade, a tabela 3 apresenta os dados, por AEDs, da população de Aparecida de Goiana acima de 15 anos que trabalha ou estuda em Goiânia. A Figura 2 indica no espaço intra-urbano a localização dessas AEDs. Com essas duas informações, podemos, em escala mais detalhada, observar quais as regiões mais populosas e com maior percentual de migração pendular. As AEDs mais distantes de Goiânia são as de número 1, 2 e 3 e as 
mais próximas as de número 14, 15, 6 e 7. As últimas estão localizadas no limite Norte de Aparecida de Goiânia, área conurbada com Goiânia, região mais povoada e de maior verticalizacão que abrigava, em 2000, 88,59\% dos apartamentos daquele município (IBGE, 2001).

Figura 2: Aparecida de Goiânia - AEDs

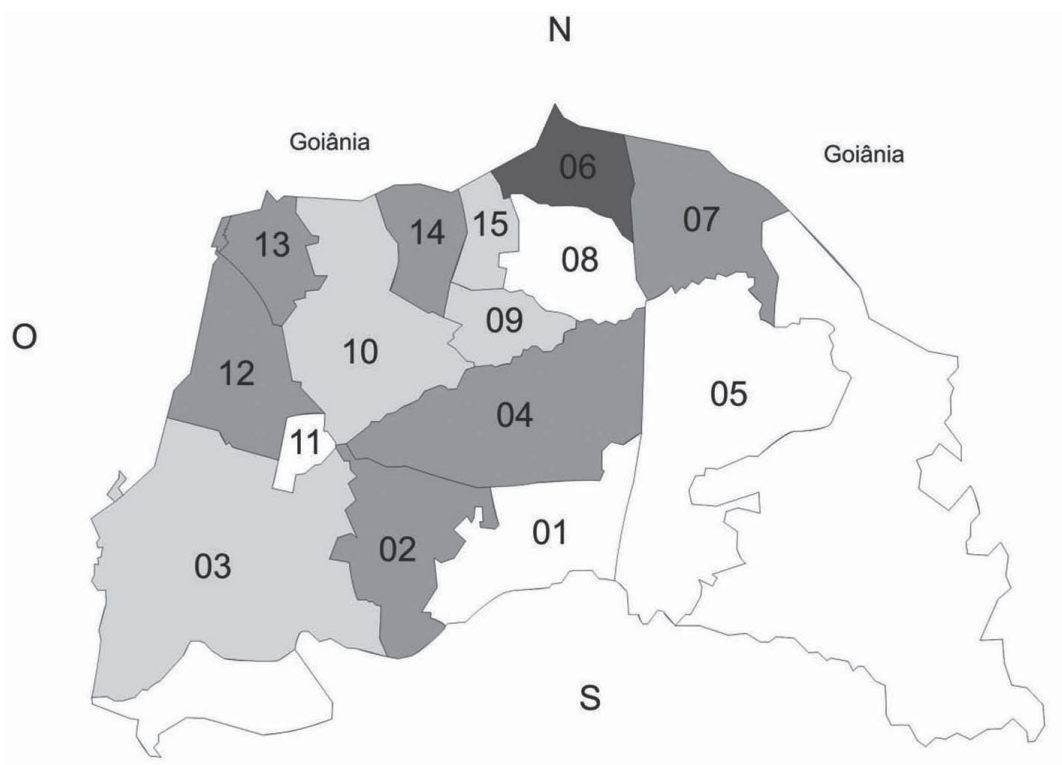

AEDs - Aparecida de Goiânia

01 - Setor Central

02 - Cidade Livre / Setor Colina Azul / Independência Mansões

03 - Setor Madre Germana / Bairro Dom Bosco / Alto Paraiso

04 - Pontal Sul / Veiga Jardim / Independência

05 - Vila Souza / Conjunto Planície / Zona Rural

06 - Jardim Esmeralda / Vila Brasília / Setor dos Afonsos

07 - Jardim Bela Vista / Santa Luzía / Olímpico /

Parque Trindade / Zona Rural

08 - Jardim Imperial / Vila Alzira / Vila Maria

09 - Papilon Park / Mansões Paraíso / Parque Veiga Jardim

10 - Morada dos Pássaros / Ponta Sul / Jd. Helvécia / B. Cardoso

11 - Jardim Tiradentes / Jardim Cascata

12 - Jd. Alto Paraíso / St. Aeroporto Sul / Bandeirantes / Goiânia Pq. Sul

13 - Setor Garavelo / Garavelo Residencial Park

14 - Cidade Vera Cruz / Conj. Sta. Fé / Jd. Viena / Mônaco / Bairro Hilda

15 - Jardim Nova Era / Cj. Cruzeiro do Sul / Cidade Satélite / São Luiz

Migracão para o pólo

Entre 1996 e 2366

Entre 3640 e 762

Entre 5091 e 6052

8597

\section{Escala Gráfica}

$5 \mathrm{~km}$

0

5

10

$15 \mathrm{~km}$ 


\begin{tabular}{|c|c|c|c|c|c|c|c|c|c|c|c|c|c|c|c|c|c|c|}
\hline & 沓 & $\begin{array}{l}0 \\
\text { Hi }\end{array}$ & $\hat{\tilde{f}}$ & $\mid \begin{array}{l}N \\
10 \\
m\end{array}$ & $\stackrel{m}{-\infty}$ & \begin{tabular}{|c|}
0 \\
$\tilde{\text { Dे }}$ \\
\end{tabular} & $\begin{array}{l}0 \\
\text { î } \\
\text { i }\end{array}$ & $\begin{array}{c}\stackrel{0}{1} \\
\text { הิ }\end{array}$ & $\stackrel{0}{\stackrel{-}{N}}$ & \begin{tabular}{l|} 
L \\
L \\
S \\
\end{tabular} & $\begin{array}{l}0 \\
\text { ते } \\
\text { ले }\end{array}$ & $\begin{array}{l}4 \\
\infty \\
\infty\end{array}$ & $\begin{array}{l}\text { os } \\
\text { ते }\end{array}$ & 1 & กิ & & 1 & 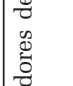 \\
\hline త్ర & $\partial^{e}$ & $\approx$ & $\vec{\sigma}$ & $\begin{array}{l}20 \\
\stackrel{2}{=}\end{array}$ & $\begin{array}{l}\infty \\
\overbrace{}^{-}\end{array}$ & \begin{tabular}{l}
0 \\
0 \\
\hdashline \\
\hdashline
\end{tabular} & $\begin{array}{l}0 \\
0 \\
0\end{array}$ & $\stackrel{10}{=}$ & 10 & $\stackrel{m}{=}$ & $\stackrel{+}{ \pm}$ & $\stackrel{m}{\sim}$ & $\begin{array}{l}10 \\
10 \\
10\end{array}$ & 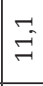 & $\begin{array}{l}\infty \\
\stackrel{0}{\ominus}\end{array}$ & $\overrightarrow{0}$ & I & \\
\hline 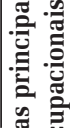 & 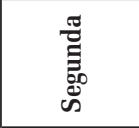 & ن & 国 & U & 目 & u & 福 & 㗧 & U. & 䀝 & 已 & U & 周 & 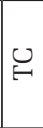 & U & 됭 & I & \\
\hline o & $\alpha^{0}$ & 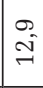 & $\begin{array}{l}0 \\
\tilde{D} \\
\tilde{N}\end{array}$ & $\widehat{\approx}$ & $\begin{array}{l}m \\
\stackrel{2}{=}\end{array}$ & $\overrightarrow{\tilde{I}}$ & $\begin{array}{l}\sharp \\
m \\
\sim\end{array}$ & $\stackrel{10}{\stackrel{10}{0}} \stackrel{0}{\circ}$ & $\stackrel{=}{=}$ & \begin{tabular}{l}
$\mathcal{N}$ \\
\multirow{H}{*}{}
\end{tabular} & $\stackrel{\substack{0 \\
\infty}}{\infty}$ & $\vec{\sigma}$ & $\stackrel{4}{5}$ & $\begin{array}{l}0 \\
\stackrel{\infty}{\sim}\end{array}$ & $\stackrel{10}{\leftrightarrows}$ & $\begin{array}{l}0 \\
\stackrel{+}{+}\end{array}$ & I & \\
\hline है & 苞 & 拎 & ن & 目 & ن & 될 & 동 & U్ & 됭 & U & ن & 同 & ن & מ & $\underset{\epsilon}{U}$ & 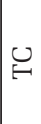 & I & \\
\hline 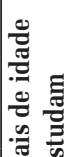 & 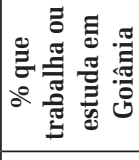 & $\begin{array}{l}0 \\
0 \\
\text { N }\end{array}$ & 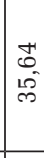 & 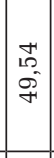 & $\begin{array}{l}\infty \\
\infty \\
0 \\
\infty\end{array}$ & $\begin{array}{l}18 \\
9 \\
9 \\
9 \\
-\end{array}$ & \begin{tabular}{l}
$\infty$ \\
$\stackrel{8}{\circ}$ \\
\multirow{4}{*}{}
\end{tabular} & 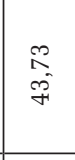 & $\begin{array}{l}0 \\
\text { d } \\
\text { s }\end{array}$ & $\begin{array}{l}8 \\
\text { f } \\
\text { f }\end{array}$ & $\stackrel{\mathbb{N}}{-}$ & $\begin{array}{l}0 \\
10 \\
0 \\
0 \\
e\end{array}$ & $\begin{array}{l}\infty \\
\infty \\
\infty \\
0\end{array}$ & 学 & 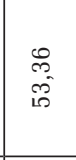 & $\begin{array}{l}\vec{\infty} \\
\text { ली }\end{array}$ & 1 & \\
\hline 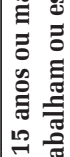 & 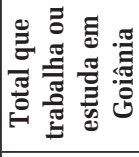 & 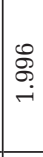 & 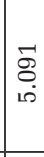 & 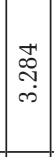 & $\begin{array}{l}\stackrel{20}{0} \\
\stackrel{\vec{*}}{10}\end{array}$ & 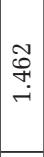 & 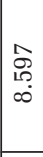 & 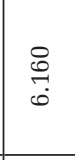 & $\begin{array}{l}\text { t } \\
\text { d } \\
\text { in }\end{array}$ & $\begin{array}{l}\vec{b} \\
\infty \\
\infty \\
\infty\end{array}$ & $\begin{array}{l}\underset{W}{ } \\
\stackrel{+}{+}\end{array}$ & $\begin{array}{l}0 \\
\mathscr{0} \\
\tilde{e} \\
i\end{array}$ & 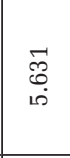 & $\begin{array}{l}\text { जै } \\
\text { เి } \\
0\end{array}$ & $\underset{\mathrm{N}}{\stackrel{N}{N}}$ & $\begin{array}{l}\text { 草 } \\
\stackrel{0}{0} \\
\text { in }\end{array}$ & $\begin{array}{l}7 \\
0 \\
-1 \\
0 \\
0\end{array}$ & \\
\hline 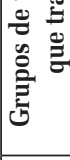 & 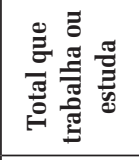 & $\stackrel{0}{\stackrel{n}{N}}$ & 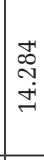 & 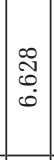 & 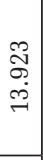 & 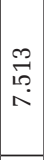 & $\begin{array}{l}0 \\
\stackrel{0}{0} \\
\text { 1. } \\
\infty \\
-1 \\
-1\end{array}$ & $\begin{array}{l}\mathscr{0} \\
\infty \\
\stackrel{0}{0} \\
\dot{I}\end{array}$ & 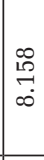 & $\begin{array}{l}0 \\
\not{D} \\
0 \\
\infty \\
\infty\end{array}$ & 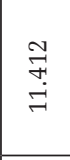 & 孛 & $\begin{array}{l}\mathscr{8} \\
\stackrel{0}{+} \\
\sigma\end{array}$ & $\begin{array}{l}8 \\
\infty \\
0 \\
10 \\
\end{array}$ & 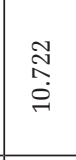 & $\begin{array}{l}0 \\
\text { L̊ } \\
+ \\
\stackrel{2}{0}\end{array}$ & $\begin{array}{l}12 \\
6 \\
-1 \\
-0 \\
-1\end{array}$ & \\
\hline 空 & 节 & 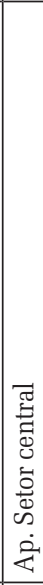 & 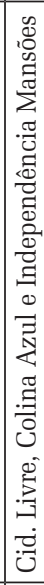 & 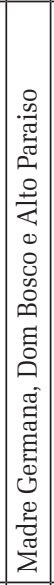 & 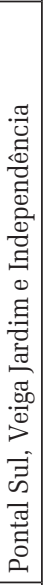 & 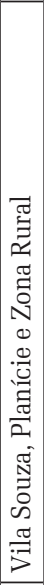 & 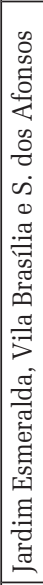 & 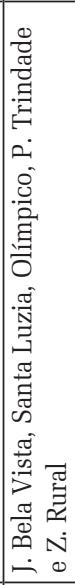 & 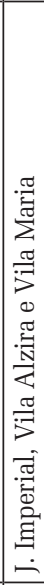 & 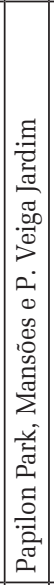 & 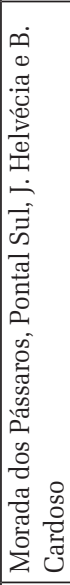 & 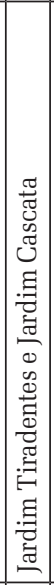 & 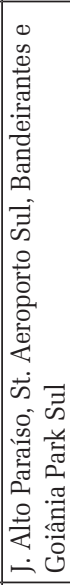 & 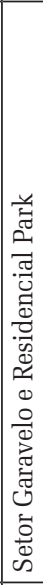 & 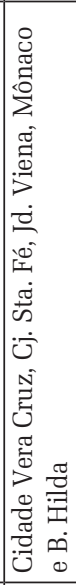 & 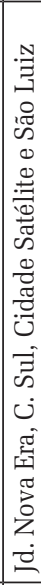 & & \\
\hline & 总 & $\sigma$ & ปิ & ஜ & J & $\stackrel{2}{\circ}$ & $\bullet$ & $\hat{o}$ & $\stackrel{\infty}{\circ}$ & 8 & $\stackrel{ }{ }$ & $\exists$ & $\stackrel{\mathcal{F}}{\sim}$ & $\stackrel{m}{\sim}$ & $\nexists$ & 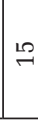 & 퓽 & \\
\hline
\end{tabular}


O mérito da pesquisa não está apenas em regionalizar os dados (população, classe de renda, moradia, infra-estrutura, emprego etc.) na escala intramunicipal. Sabemos que a migração pendular reflete o nível de renda a as condições de moradia dos indivíduos, aquelas virtualidades a que se referiu Levy (2000). Assim, buscamos incorporar na análise da mobilidade a posição social dos indivíduos, utilizando as Categorias Ocupacionais. ${ }^{7}$ As colunas 6 e 8 da tabela 4, indicam os percentuais de participação das duas principais Categorias Ocupacionais em cada AEDs, aparecendo apenas sete das 24 consideradas na pesquisa: Operários da Construção Civil (OCC), Ocupações de Escritório (OE), Prestadores de Serviços (PS), Prestadores de Serviços Especializados (PSE), Trabalhadores Domésticos (TD), Trabalhadores da Indústria Tradicional (TIT) e Trabalhadores do Comércio (TC). Somadas as duas principais contribuições em cada AEDs, temos uma faixa que vai de 21,6\% (AEDs 8) até 42,7\% (AEDs 2). Isso significa que 42,7\% das pessoas ocupadas da AEDs 2 são Operário da Construção Civil (OCC) e/ou Trabalhadores Domésticos (TD). Também aponta um quadro socioespacial mais homogêneo do que aquele da AEDs 8. Nessa, por exemplo, constata-se uma maior heterogeneidade das Categorias Ocupacionais, o que reflete, por outro lado, um território mais heterogêneo, especialmente do ponto de vista da moradia.

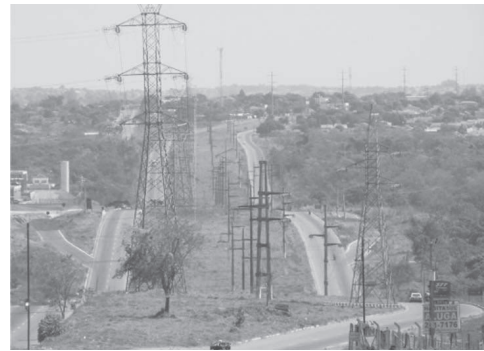

AEDs 4

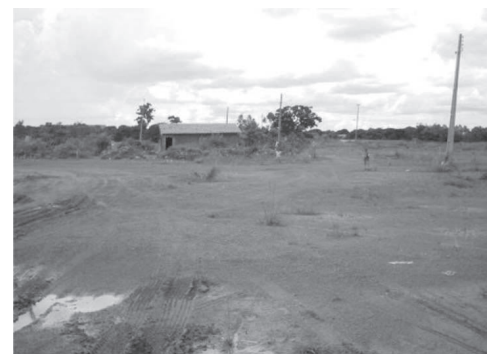

AEDs 06

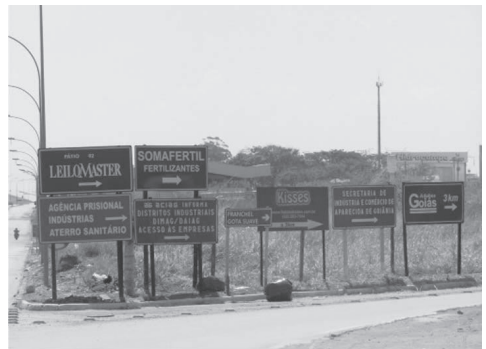

AEDs 5

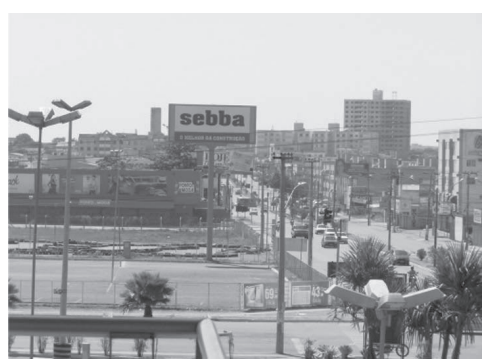

AEDs 10 
Operários da Construção Civil (OCC) é a categoria mais representativa em Aparecida de Goiânia, estando em primeiro lugar em seis AEDs e em segundo lugar em outras seis. Logo depois vem os Prestadores de Serviços Especializados (PSE), com três em primeiro e uma em segundo, sendo seguido dos Trabalhadores Domésticos (TD), em primeiro em uma AEDs e em segundo em quatro.

Do ponto de vista da análise da mobilidade, as informações permitem relacionar o lugar de residência-deslocamento, a distância em relação à Goiânia e o perfil ocupacional. É necessário advertir, no entanto, que os dados sobre deslocamento não estão desagregados por Categoria Ocupacional, o que, de certo modo, não prejudica a análise, uma vez que existe uma margem considerável de coincidência entre a população acima de 15 anos que trabalha e/ou estuda e o perfil profissional médio de cada AEDs. Nesse sentido, a análise dos dados da tabela 3 , em conjunto com a figura 2 , revela que:

a) As AEDs 6 e 7, primeira e segunda com maior deslocamento, em números absolutos, são aqueles em que os Prestadores de Serviços (PS) e as Ocupações de Escritório (OE) exercem maior peso, fato que se justifica por ser esta a região com maior concentração de equipamentos de comércio e serviços e, por outro lado, a mais próxima de Goiânia. O perfil do deslocamento, portanto, faz par com o perfil das ocupações dessas AEDs, configurando um território ocupado por pessoas com renda superior no município. A maior renda deriva das ocupações terciárias exercidas tanto em Goiânia quanto na própria AEDs. Na avenida Rio Verde, limite de Goiânia com Aparecida de Goiânia, estão concentrados serviços bancários, postos de gasolina, locadoras, revendas de carros, farmácias, grandes supermercados, cinemas, casas lotéricas, shopping etc., que atende a demanda do município. Trata-se do centro econômico propriamente dito.

b) As AEDs 2 e 3 é onde verifica-se maior participação de Operários da Construção Civil (OCC) e Trabalhadores Domésticos (TD). Também são, respectivamente, aquelas mais distantes de Goiânia. Pode-se deduzir que esse é o perfil predominante das pessoas que migram para Goiânia. Na AEDs 3 , por exemplo, mais de $49,54 \%$ das pessoas que trabalham ou estudam, em 2000, exerciam essas atividades em Goiânia. Em geral, essas AEDs apresentam alto grau de migração intra-metropolitana e menor rendimento mensal. Na AEDs 3, 59,6\% dos migrantes são intra-metropolitanos, dado que coaduna com o fato de essa região ter recebido um significativo excedente populacional de Goiânia. 
c) A proximidade/distância de Goiânia é influenciada pelo perfil ocupacional, uma vez que as ocupações, na medida em que se afastam do limites Sul de Goiânia são aquelas que exigem menor qualificação. As AEDs 2, 3 e 11, é onde estão localizados os bairros menos valorizados pelo mercado imobiliário e, ao mesmo tempo, o maior estoque de lotes vagos. Esse dado é importante, pois afirma a forte influência do mercado imobiliário na regulação e distribuição da população no espaço urbano.

d) As AEDs com menor \% de deslocamento e com menor relação funcional com Goiânia são a 1 e a 5 . A primeira esta sobre influencia, em grande parte, da região central-tradiconal de Aparecida de Goiânia e a segunda inclui a zona rural, fatores que influíram nos baixos índices de deslocamento. Interessante notar o perfil ocupacional da AEDs 5, com destacada participação do setor secundário. Nesta AEDs esta localizado o Distrito Industrial de Aparecida de Goiânia, que abriga diversas industrias dos setores químico, metalúrgico, alimentar, gráfico, construção civil, logística etc. Seu limite é demarcado pela BR-153, fator locacional importante, que facilita o escoamento da produção. Esta é a AEDs de menor porcentagem de deslocamento para Goiânia, com 19,45\% da população que trabalha e/ou estudo. Podemos deduzir que a mão de obra predominante, especialmente empregada no setor secundário, reside no município Aparecida de Goiânia.

e) Comparando duas categorias bem distintas, Trabalhadores Domésticos (TD) e Ocupações de Escritório (OE), percebe-se que os primeiros estão mais próximos e os segundos mais distantes, fato que implica em maior gasto de tempo e dispêndio de recurso justamente daquelas Categorias Ocupacionais com menor poder aquisitivo. As AEDs 2 e 3, as mais distantes, são aquelas com menor porcentagem de família na faixa de renda acima de 3 salários mínimos, em 2000, com 1,8\% e 1,3\%, respectivamente (IBGE, 2001). Já a AEDs 6 e 15, são aquelas que apresentam a maior participação percentual nessa faixa de renda, com $29,1 \%$ e $17,2 \%$, respectivamente.

Uma das hipóteses consideradas foi que o deslocamento pendular na RMG reflete a condição social dos indivíduos, o que resulta, por outro lado, no maior distanciamento social e geométrico das áreas onde está concentrada a oferta de emprego. Também estão distantes das áreas dotadas de melhor infra-estrutura urbana e equipamentos sociais. Os dados preliminares da pesquisa confirmam essa premissa. Basta citar que as AEDs 2, 4, 1011 e 12, onde aparecem o par Operários da Construção Civil (OCC) e Trabalhadores Domésticos (TD), são aquelas onde verifica-se as maiores percentagens de 
deslocamento e a maior distancia de Goiânia. Na AEDs 3, uma das maiores em termos de área, é onde se encontra a maior percentual de analfabetos, de domicílios com carência de água, além de ser aquela com menor renda per capita e com a maior número, proporcionalmente, de negros/pardos $(65,9 \%)$, um corte que, certamente, possibilita inferir sobre as características comuns dos grupos excluídos que migram diariamente para Goiânia (IBGE, 2001).

A lógica da segregação resume-se em que as pessoas que mais migram são aquelas que residem mais distantes e em piores condições sociais. Vejamos como uma reportagem veiculada no Jornal $O$ Popular trata desse assunto:

Embora sempre tenha trabalhado na capital, a cozinheira Lucélia Esterlita de Farias, 35, tem se distanciado cada vez mais do local onde trabalha. Há três meses, mudou-se do Jardim Tiradentes, em Aparecida de Goiânia, para Aragoiânia. Ela tem de pegar seis ônibus por dia para ir de casa para o emprego e voltar, à noite, para Aragoiânia. (O POPULAR, p. 3)

A cozinheira Lucélia morava na AEDs 11, onde, segundo dados da pesquisa, residiam, em 2000, 6.471 pessoas acima de 15 anos de idade, das quais 2.366 deslocavam-se diariamente para Goiânia. De lá mudou-se para Aragoiânia, cidade que dista $42 \mathrm{~km}$ de Goiânia. A viagem ficou mais distante e mais demorada. Dona Lucélia partilha do drama de inúmeros outras empregadas domésticas, pedreiros, faxineiros, porteiros, operários, que abdicam diariamente dos seus territórios de partida para "ganhar" a vida em Goiânia. Essa situação configura uma realidade comum nos espaços metropolitanos brasileiros. Uma realidade que precisa entrar, urgentemente, na agenda de preocupação dos governos “responsáveis” pela gestão dos espaços metropolitanos.

\section{Palavras finais}

A análise empreendida sobre a mobilidade na Região Metropolitana de Goiânia envolveu considerações sobre o território de destino (o local de trabalho, de estudo, onde vão saldar as demandas diárias) e os territórios de partida (municípios com característica próprias da periferização, com pouca oferta de emprego, serviços e infra-estrutura). A regionalizacao dos dados sobre deslocamento pendular e estrutura ocupacional, possibilitou um leitura mais detalhada do município de Aparecida de Goiânia. Essa leitura afirma a 
dependente deste municípios em relação à Goiânia. Entretanto, não se trata de um território homogêneo. Essa dependência é seletiva. Há um padrão de organização espacial onde verificamos diferenças significativas entre a área conurbada com Goiânia, o eixo da BR-153, as áreas mais centrais (menos povoadas) e a faixa sudoeste do município. Todas essas áreas, de maneira geral, estão integradas diferencialmente, o que significa que estabelecem relações funcionais de dependência com a metrópole.

É a mobilidade que oferece a aparente unidade desses territórios heterogêneos e nos permite falar em Região Metropolitana. É a mobilidade que garante, também aparentemente, o acesso diferencial ao território de destino (Goiânia). Assim, a mobilidade permite a circulação no interior da RMG, mas não a circulação com qualquer propósito. Na acepção de Lefebvre (1999), a mobilidade que nos referimos permite a circulação para a troca e não para o uso, o que confirma, para utilizar suas palavras, a condição de "semicolônias" das cidades satélites. É dessa forma que a mobilidade passa a se constituir, como bem anotou Raffestin (1997), um "trunfo do poder". Um trunfo que possibilita o controle dissimulado dos territórios de partida, perpetuando a segregação das camadas mais pobres. O trunfo também reside em fazer que a população excluída acredite que a melhoria nas condições de mobilidade permitirá o acesso igual ao território de destino. $\mathrm{O}$ trunfo reside em perpetuar a divisão do trabalho que tem, por sua vez, um pressuposto territorial muito claro. O trunfo reside em, para utilizar as palavras de Debord (1997), suprimir a distancia apenas como separação espetacular.

\section{Notas}

1 Sobre o processo de constituição das Regiões Metropolitanas, pode-se encontrar um bom debate em Ribeiro (2000).

2 A centralidade recebeu atenção de H. Lefebvre. Nas suas palavras: "Descobrimos o essencial do fenômeno urbano na centralidade. Mas na centralidade considerada como o movimento dialético que a constitui e a destrói, que a cria ou a estilhaça. Não importa qual ponto possa tornar-se central, esse é o sentido do espaço-tempo urbano. A centralidade não é indiferente ao que ela reúne, ao contrario, pois ela exige um conteúdo. E, no entanto, não importa qual seja esse conteúdo. Amontoamento de objetos e de produtos nos entrepostos, montes de frutas nas praças de mercado, multidões, pessoas caminhando, pilhas de objetos variados, justapostos, superpostos, acumulados, eis o que constitui o urbano” (1999, p. 110).

3 A pesquisa sobre deslocamentos adotou como corte as atividades de trabalho e de estudo. Essa opção desconsidera o fato da ocorrência de deslocamentos para outros fins, como lazer e saúde, destacando apenas os deslocamentos pendulares, mais freqüentes. 
4 Segundo Haesbaert (2005, p. 37): “O domínio do capital financeiro, especulativo, que não entra no setor efetivamente produtivo, gerador de empregos, a economia pautada em setores de alta tecnologia, poupadores de força de trabalho, a fragilização do 'Estado providência' ou do bem estar social (que também atuava como válvula de escape, empregando em épocas de crise), em nova da privação e da globalização neoliberal, tudo isso se agrega para criar uma massa de expropriados cuja reprodução e mobilidade passam a ser consideradas um problema crescente para os grupos dominantes".

5 Essa distância tem como referencia as áreas centrais dos municípios. Um estudante que resida em Aragoiânia e estude na UFG percorre, diariamente, aproximadamente $100 \mathrm{~km}$. Em termos de tempo pode-se gastar até 3,5 horas diárias no deslocamento.

6 Pesquisa financiada pelo Edital do CNPq Instituto Milênio/2005, sob coordenação nacional do Observatorio da Metrópolis, IPPUR-RJ. Uma das preocupações da pesquisa reside em mensurar e comparar os níveis de segregação utilizando como elemento de classificação e descrição a tipologia socioespacial. Segundo Ribeiro (2005, p. 96): “A tipologia socioespacial objetiva caracterizar socialmente as áreas geográficas da cidade. A aplicação do método da tipologia na analise da segregação espacial permite agrupar as unidades de acordo com um conjunto de variáveis consideradas centrais na descrição e na interpretação dos princípios da divisão do espaço."

7 O conjunto de profissões definidas tem como base a Classificação Brasileira de Ocupações. Na pesquisa desenvolvida pelo Observatório das Metropolis estão sendo utilizadas 24 classificações, assim definidas: agricultores, grandes empregadores, dirigentes do setor publico, dirigentes do setor privado, pequenos empregadores, ocupações artísticas ou similares, profissionais autônomos de nível superior, profissionais empregados de nível superior, profissionais estatutários de nível superior, professores de nível superior, ocupações de escritório, ocupações de supervisão, ocupações técnicas, ocupações médias da saúde e educação, ocupações de segurança publica, justiça e correios, trabalhadores do comercio, prestadores de serviços especializados, trabalhadores da indústria moderna, trabalhadores da indústria tradicional, operários dos serviços auxiliares, operários da construção civil, trabalhadores domésticos e ambulantes e catadores.

\section{Referências}

ARRAIS, T. A. Geografia contemporânea de Goiás. Goiânia: Editora Vieira, 2004.

BADIE, Bertrand. O fim dos territórios - ensaio sobre a desordem internacional e sobre a utilidade social do respeito. Lisboa: Instituto Piaget, 1995.

BAUMAN, Zigmunt. Globalização - as conseqüências humanas. Rio de Janeiro: Zahar Editores, 1999.

BORJA, Jordi. Grandes projetos metropolitanos: mobilidade e centralidade. In: Os centros das cidades - reflexões e propostas para a cidade democrática do século XXI. São Paulo: Editora Terceiro Nome, 2001.

DEBORD, Guy. A sociedade do espetáculo. Rio de Janeiro: Contraponto, 1997.

GOIÁS. Anuário Estatístico do Estado de Goiás - 2003. Goiânia: SEPLAN, 2003c. 
HAESBAERT, R. Concepções de território para entender a desterritorialização. In: Território, territórios. Niterói: Editora da UFF, Programa de Pesquisa e Pós-Graduação em Geografia - UFF, 2002.

HAESBAERT, R. O mito da desterritorialização - do 'fim dos territórios' à multiterritorialidade. Rio de Janeiro: Bertrand Brasil, 2004.

HAESBAERT, R. Precarização, reclusão e "exclusão" territorial. Terra Livre - Temperos da Geografia. Ano 20, v. 2, n. 23. Goiânia, 2005.

IBGE. Censo demográfico 2000. (METRODATA). Rio de Janeiro: IBGE, 2001.

IBGE. Censo demográfico 2000 - migração. Rio de Janeiro: IBGE, 2003.

LEVY, Jacques. Os novos espaços da mobilidade. In: GEOGRAPHIA. Revista da Pós-Graduação em Geografia da UFF. Ano 3, n. 6. Niterói/RJ, 2002.

LEFEBVRE, H. A revolução urbana. Belo Horizonte: Editora da UFMG, 1999.

MASSEY, Doreen. Um sentido global do lugar. In: ARANTES, A. O. O espaço da diferença. Campinas, SP: Papirus, 2000.

MOYSÉS, Aristides. Goiânia: metrópole não planejada. Goiânia: UCG, 2005.

OHMAE, K. O fim do Estado-Nação. Rio de Janeiro: Campus, 1996.

O drama dos exilados. Jornal O Popular. Caderno Cidades. 24/10/2004.

RIBEIRO, Luiz César de Queiroz (Org.). O futuro das metrópoles: desigualdades e governabilidade. Rio de Janeiro: Revan, FASE, 2000.

RIBEIRO, Luiz César de Queiroz. Segregação residencial: teorias, conceitos e técnicas. In: MOYSES, Aristides (Org.). Cidade, segregação urbana e planejamento. Goiânia: Ed. UCG. 2005.

RIBEIRO, Valéria Maria. Transporte coletivo urbano e qualidade de vida. Dissertação de mestrado. Goiânia: IESA, UFG, 2000.

RAFFESTIN, C. Por uma geografia do poder. São Paulo: Ática, 1993.

SACK, Robert. Human territoriality. Cambridge: Cambridge University Press, 1986.

SANTOS, Milton. O espaço dividido. Rio de Janeiro: F. Alves, 1979.

SOUZA, Marcelo J. Lopes. O território: sobre espaço e poder, autonomia e desenvolvimento. In: CORREAA, R. Lobato et al. (Org.). Geografia: conceitos e temas. Rio de Janeiro: Bertrand Brasil, 1995.

TADEU ALENCAR ARRAIS - Professor adjunto do IESA-UFG, pesquisador do Observatório das Metrópoles (Núcleo Goiânia) e coordenador do Observatório Geográfico de Goiás (www.observatoriogeogoias.com.br).

Recebido para publicação em abril de 2006 Aceito para publicação em agosto de 2006 